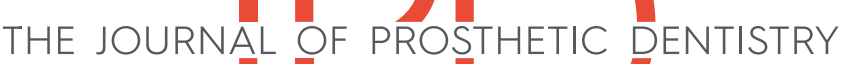

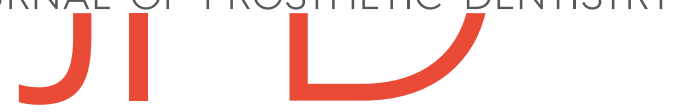

RESEARCH AND EDUCATION

\section{Structural and quantitative analysis of a mature anaerobic biofilm on different implant abutment surfaces}

\author{
Erica Dorigatti de Avila, DDS, PhD, ${ }^{a}$ Mario Julio Avila-Campos, MSc, PhD, \\ Carlos Eduardo Vergani, DDS, MSc, $\mathrm{PhD}^{c}$ Denise Madalena Palomari Spolidório, $\mathrm{MSc}, \mathrm{PhD}^{\mathrm{d}}$ and \\ Francisco de Assis Mollo Jr, DDS, MSc, PhD
}

Bacteria grow on both natural (tooth, mucosa) and artificial (restorative dental materials, ${ }^{1}$ dental implants) surfaces as biofilms, which are highly organized microbial communities embedded in polymeric matrices. Although a number of other factors seem to be modifying disease expression, ${ }^{2}$ the accumulation of biofilm on materials adjacent to the gingival tissue is a primary initiating factor for periodontal diseases. $^{3}$ When individuals lose their teeth because of periodontal disease, pathogenic bacteria remain inside the oral cavity. When dental implants replace a hopeless tooth, the microorganisms on the dental surfaces may colonize the implant abutment surfaces, similar to what happens on natural teeth, resulting in periimplant disease. ${ }^{4}$ Periimplantitis is a lesion resulting from an inflammatory reaction induced by pathogenic bacteria around the implant surfaces. ${ }^{5}$ Periimplant tissue inflammation is currently considered a major contributor to Dent 2016;115:428-436)

\begin{abstract}
Statement of problem. The longevity of dental implants depends on the absence of inflammation in the periimplant tissue. Similar to teeth, pathogenic bacteria can adhere on implant abutment surfaces and cause periimplant disease and consequently implant loss.

Purpose. The purpose of this in vitro study was to evaluate the influence of physical and chemical properties of 2 common materials used as implant abutments, titanium ( $\mathrm{Ti})$ and zirconia $\left(\mathrm{ZrO}_{2}\right)$, and the use of bovine enamel (BE) as a positive control on biofilm formation.

Material and methods. Biofilm formation was analyzed by growing Porphyromonas gingivalis and Fusobacterium nucleatum as monospecies and mixed species biofilms on the surfaces. The mean roughness $\left(R_{a}\right)$ and surface free energy were evaluated for each material. Mature biofilm, formed after 7 days of incubation, was analyzed quantitatively and qualitatively by colony-forming unit and confocal laser scanning microscopy.
\end{abstract}

Results. The mean roughness in all disks was $\leq 0.21 \mu \mathrm{m}$ and did not affect the bacterial adhesion. Titanium showed a greater degree of hydrophilicity compared with BE after 90 minutes of immersion in saliva. The surface free energy did not show differences, with the highest values for $\mathrm{BE}$. Monospecies biofilms formed by $P$. gingivalis on $\mathrm{Ti}$, and mixed species biofilm on $\mathrm{ZrO}_{2}$ exhibited small numbers of cells on disk surfaces. By confocal imaging, the mixed species biofilm appeared as a thin layer on $\mathrm{ZrO}_{2}$ surfaces.

Conclusions. Material surfaces could have a significant impact on biofilm formation. $\mathrm{ZrO}_{2}$ implant abutment surfaces showed a decrease in anaerobic biofilm compared with $\mathrm{Ti}$ and BE. (J Prosthet

implant loss. ${ }^{6,7}$ Periimplantitis is estimated to occur in approximately $17 \%$ of implants after 10 to 16 years of follow-up. ${ }^{8}$

The development of inflammation around oral implants is associated with the accumulation of specific bacterial biofilms. Even though more than 700 bacterial

Supported by grant 2011/05106-6 (to E.D.d.A.) from São Paulo Research Foundation (FAPESP).

aPostdoctoral Fellow, Department of Dental Materials and Prosthodontics, School of Dentistry at Araraquara, São Paulo State University (UNESP), Araraquara, Brazil.

brofessor, Department of Microbiology, Institute of Biomedical Science, University of São Paulo, São Paulo, Brazil.

${ }^{c}$ Professor, Department of Dental Materials and Prosthodontics, School of Dentistry at Araraquara, São Paulo State University (UNESP), Araraquara, Brazil.

${ }^{d}$ Adjunct Professor, Department of Physiology and Pathology, School of Dentistry at Araraquara, São Paulo State University (UNESP), Araraquara, Brazil.

${ }^{e}$ Adjunct Professor, Department of Dental Materials and Prosthodontics, School of Dentistry at Araraquara, São Paulo State University (UNESP), Araraquara, Brazil. 


\section{Clinical Implications}

Periimplant disease is mediated and modulated by the host, but pathogenic bacteria are responsible for starting the inflammatory process. The physical-chemical properties of the implant abutment materials affect the biofilm formation. Ti and bovine enamel surfaces showed an increase of anaerobic biofilm compared with $\mathrm{ZrO}_{2}$.

species can colonize the oral cavity, ${ }^{9}$ only a few are implicated in the pathogenesis of periodontal disease. ${ }^{10}$ Porphyromonas gingivalis is associated with chronic periodontitis and can be detected in up to $85 \%$ of the disease sites. ${ }^{11}$ In contrast, healthy sites show low numbers of this microorganism. The presence of $P$. gingivalis in a periodontal pocket may predict imminent disease progression. ${ }^{12}$ This organism expresses several virulence factors implicated in periodontal inflammation. ${ }^{13}$ The pathogenic role of this bacterium in periodontal disease depends on its ability to bind to the host's cells, the acquired pellicle, and other bacteria. Fusobacterium nucleatum is also commonly associated with periodontal disease and implant failure ${ }^{14}$ and has been shown to exhibit coaggregation with different bacteria, including $P$. gingivalis, which plays a central role in the development of the dental biofilm. Its opportunistic characteristic has been shown in diseased periodontal and periimplant sites because $F$. nucleatum serves as a bridge between the early and late colonizers. ${ }^{15}$

Prosthetic components, such as implant abutments, have an important effect on microbial adhesion, and the type of material can help increase or reduce the bacterial attachment and biofilm formation. ${ }^{16-19}$ The most relevant surface properties influencing the bacterial attachment are roughness, wetting, and surface energy. ${ }^{20-24}$ Overall, these physicochemical characteristics have been thought to change the implant and prosthetic component surfaces in an attempt to reduce the adherence of pathogenic microorganisms. ${ }^{25-28}$ Titanium (Ti) is still considered the reference standard material because of its physical characteristics, including biocompatibility, stability, and corrosion resistance. The high demand for esthetic restorations, however, has favored the introduction of yttriastabilized zirconia $\left(\mathrm{ZrO}_{2}\right)$ ceramic implant abutments. In vivo and in vitro studies of the biofilm formation on titanium and zirconia surfaces have been reported ${ }^{29-34}$; however, knowledge is still limited about possible differences in the bacterial adhesion mechanisms to metal compared with ceramic surfaces. Therefore, this study investigated the anaerobic biofilm formation on 2 implant abutment surfaces, titanium and zirconia. The hypothesis was that the physical chemical composition inherent in each material interferes in the ability of microorganisms to adhere to the different tested substrates.

\section{MATERIAL AND METHODS}

Pure titanium and yttria-stabilized zirconia disks (Conexao Sistema de Protese Ltd) $(8 \mathrm{~mm}$ in diameter and $2 \mathrm{~mm}$ in thickness) were used as the experimental groups, and bovine enamel (BE) disks were used as a positive control. Ti and $\mathrm{ZrO}_{2}$ were prepared by machining, and enamel disks were cut from bovine incisors. The BE specimens were stored in $0.1 \%$ thymol solution at $4^{\circ} \mathrm{C}$ to inhibit the microbial activity until use. Enamel disks were obtained by using a $10-\mathrm{mm}$ diamond drill for glass thread (Dinser Diamond Tools Ltd), coupled to the drill bench vise (FSB model 16; Schulz, chuck taper DIN 238-B18). The disk surfaces were prepared with abrasive paper of 800,1200 , and 4000 grit to polish the surface and reduce the roughness (grain 220; T469-SF-Noton; Saint-Gobam Abrasives Ltd).

The mean roughness $\left(R_{a}\right)$ of all disks was quantitatively analyzed with a portable roughness tester (Mitutoyosurftest SJ-401; Mitutoyo Corp) with an accuracy of $0.01 \mathrm{~mm}$, a reading length of $2.5 \mathrm{~mm}$, an active tip speed of $0.5 \mathrm{~mm} / \mathrm{s}$, and a radius of $5 \mu \mathrm{m}$. To verify the reliability of the results, a device was used to stabilize and standardize the analysis. The reading at 2 different times and the intraexaminer reproducibility were assessed, calculating the intraclass correlation coefficient with a confidence interval of $95 \%$.

The disks were immersed in $800 \mu \mathrm{L}$ of unstimulated human saliva for 90 minutes, then washed once with $1 \mathrm{~mL}$ of sterile phosphate-buffered saline (PBS), dried at room temperature, and stored in a 24-well plate before the surface free energy (SFE) measurement with the Sessile-Drop method (Optical Contact Angle Measurements SCA-20; DataPhysics Instruments $\mathrm{GmbH}$ ). To this end, 4 wet agents were selected from more to less polar solvents: water, ethylene glycol, polyethylene glycol, and diiodomethane. To assess the reproducibility of the experiment, 5 disks of each material were tested, and the test was repeated 3 times in each liquid. The average value of the contact angle was regarded as the mean value of the contact angle for each specimen, and software (SCA-Software/OCA-20; DataPhysics Instruments $\mathrm{GmbH}$ ) was used for the SFE calculation using the concept of polar and dispersion components to the Owens, Wendt, Rabel, Kaelble (OWRK) method. ${ }^{35}$

The surface and elemental compositions were analyzed with a field emission environmental scanning electron microscope (SEM) (FEG-MEV; Jeol 7500F model) and energy-dispersive $\mathrm{x}$-ray spectroscopy (EDS), and the data were examined by a specialist (M.J.J.). For this end, 3 disks of each group was used. The specimens were positioned inside the SEM, and 5 areas from each 
specimen were arbitrarily chosen by a masked examiner. All disk surfaces were taken from their original package delivered directly from the supplier. Each zirconia disk was attached to an aluminum stub with adhesive conductive carbon tape. Images were made with both secondary and backscattered electrons. For EDS analysis, $7 \mathrm{kV}$ accelerating voltage was used to improve peak/ background ratio for light elements. Three disks of each group were used.

After the disks were cleaned, the specimens were arbitrarily distributed according to group and placed inside envelopes. Each element in the population (total number of specimens) had a known and equal probability of selection. The disks were sterilized overnight using gamma irradiation at $25 \mathrm{kGy}$ from an artificial cobalt 60 source in a nuclear reactor (ISO-11137: 2006) (Energy and Nuclear Research Institute, IPEN).

Unstimulated saliva specimens were collected on the morning from 1 healthy donor adult aged 30 years, according to an approved protocol (Research Ethic Committee Process No. 051/2012). ${ }^{36,37}$ The donor had not taken any medications 3 months before the specimen collection and did not exhibit active periodontal disease. ${ }^{37,38}$ The collected saliva was placed on ice and clarified by centrifuging at $45 \mathrm{~N}$ for 15 minutes at $4^{\circ} \mathrm{C}$. The supernatant was sterilized by filtration, membrane pore size $0.22 \mu \mathrm{m}$ (Millipore), and stored at $-20^{\circ} \mathrm{C}$ until use. The $P$. gingivalis ATCC 33277 and F. nucleatum ATCC 25586, used in this study, were grown on blood agar supplemented with hemin $(10 \mathrm{mg} / \mathrm{mL})$ and menadione $(5 \mathrm{mg} / \mathrm{mL})$ for 10 days in an anaerobic chamber (atmosphere of $85 \% \mathrm{~N}_{2}, 10 \% \mathrm{H}_{2}$, and $5 \% \mathrm{CO}_{2}$ ). One colony from each bacterium was added to brain-heart infusion (BHI) broth supplemented with hemin and menadione and incubated for 48 hours in an anaerobic chamber. After growth, aliquots were transferred to another tube with BHI to supplement the growth curve determination.

To allow pellicle formation, the disks were placed into the well with saliva at room temperature for 90 minutes. The disks were washed once with sterile PBS, transferred to a new 24-well plate with culture medium in monospecies and mixed species, and kept under anaerobic conditions for 24 hours. After the adhesion period, the disks were washed twice with sterile PBS, placed into a new 24-well plate with BHI medium, supplemented, and kept for 7 days under anaerobic conditions. During this time, the medium was changed every 48 hours. Then the disks were removed from the plate, washed twice with PBS, and analyzed by colonyforming unit $(\mathrm{CFU} / \mathrm{mL})$ and confocal laser scanning microscopy (CLSM).

In sequence, the disks were washed twice, then placed in a tube with $2.5 \mathrm{~mL}$ of PBS to detach the biofilm via ultrasound for 20 minutes (Ultrasonic;

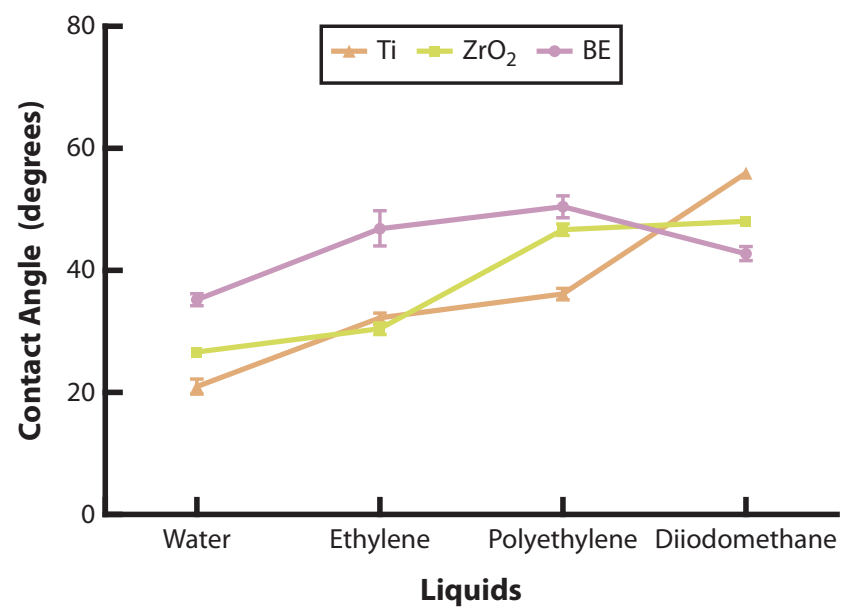

Figure 1. Effect of material surface on contact angle for different liquids: water, ethylene glycol, polyethylene glycol, and diiodomethane (brown) $\mathrm{Ti}$, (green) $\mathrm{ZrO}_{2}$, and (purple) bovine enamel.

1440 Plus). Serial dilutions were performed, and $25 \mu \mathrm{L}$ of each dilution was plated in duplicate on blood agar supplemented to verify the bacterial growth. The plates were kept under anaerobic conditions for 15 days. The $\mathrm{CFU} / \mathrm{mL}$ was determined, and its reproducibility was evaluated by photography. Images were analyzed 2 different times at a 2 -week interval. The experiments were performed in quadruplicate with 3 repetitions, giving 12 specimens.

\section{CLSM and ImageJ analysis}

Before CLSM analysis, the disks were sequentially rinsed twice with $1 \mathrm{~mL}$ of sterile PBS to remove the nonadherent bacteria. To visualize the biofilm and viable cells and to assess their thickness, cell populations were stained for 15 minutes using $800 \mu \mathrm{L}$ Live/Dead BacLight Bacterial Viability Kit (Invitrogen Corp) for each specimen. The final concentrations were Syto- $9=0.01 \mathrm{mM}$ and propidium iodide $=0.06 \mathrm{mM}$. In each experiment, exciting laser intensity, background level, contrast, and electronic zoom size were maintained at the same level. Three specimens of each group were used for this end. The disks were placed on a glass coverslip, with the surface to be analyzed in contact with the glass, and 3 areas from each disk were arbitrarily chosen by a masked examiner. A series of optical cross-sectional images was acquired at $1 \mu \mathrm{m}$ deep intervals from the surface through the vertical axis of the specimen by using a computercontrolled motor drive. The confocal images were then exported to ImageJ 1.48 freeware (National Institutes of Health; http://imagej.nih.gov/ij/download.html), and the density of the biomass was measured by the intensity of the pixels. First, the background was subtracted to remove the noise and split the color channel images. Subsequently, the number of live bacterial cells (green 
color) was estimated by counting fluorescence-specific pixels in digital fluorescent images.

\section{Data analyses}

Raw data were analyzed with software (Graph Pad Prism; GraphPad Software Inc). Descriptive statistics were used to calculate the mean and SD. Data among groups were analyzed by 1-way ANOVA, followed by the post hoc Tukey HSD test for multiple comparisons $(\alpha=.05)$.

\section{RESULTS}

Disk roughness was assessed by dispersion graphic to display the main pattern in the distribution of the data. Data beyond the line were excluded and the standard roughness values were included. The effect of surface roughness variables on biofilm formation was as follows: for Ti disks, $\mathrm{R}_{\mathrm{a}}=0.21 \pm 0.06 \mu \mathrm{m}$; for $\mathrm{ZrO}_{2}$ disks, $\mathrm{R}_{\mathrm{a}}=0.22$ $\pm 0.03 \mu \mathrm{m}$; and for $\mathrm{BE}$, for which the readings were made in perpendicular directions where the disk roughness was included as a positive control, the values ranged from 0.05 to $0.1 \mu \mathrm{m}$.

Contact angles were measured to evaluate the wettability of the different surfaces with a saliva coat. The contact angle for the sessile water drops on all the surfaces was less than 50 degrees, and therefore all of them can be considered as hydrophilic materials. ${ }^{39}$ In contrast, the Ti surface presented more lyophobic characteristics than others because of the higher contact angle formed between the surface and diiodomethane, a nonpolar liquid (Fig. 1). On the basis of the results of the OWRK method, all material surfaces presented similar SFE values as determined by the intersection of the line with the y-axis, with $\mathrm{BE}$ and $\mathrm{ZrO}_{2}$ presenting the highest numbers 3.1 and $3.2 \mathrm{~mJ} \mathrm{~m}^{-2}$.

SEM $(\times 500)$ revealed a homogenous surface, roughened for Ti and smoothed for $\mathrm{ZrO}_{2}$. Ti surfaces showed a circular configuration of alternating plane, flattened, and rough surface areas (Fig. 2A), whereas for $\mathrm{ZrO}_{2}$, a spherical shape was observed in granules (Fig. 2B). In contrast, for $\mathrm{BE}$, a higher magnification showed smooth surfaces and some cracks, a common characteristic in enamel (Fig. 2C). ${ }^{40}$ EDS identified the chemical elements in each material surface. Oxygen and titanium were found in $\mathrm{Ti}$, and oxygen with zirconium elements was present in $\mathrm{ZrO}_{2}$. BE showed calcium, phosphorus, and oxygen in its composition.

After 7 days of incubation, an ANOVA performed for bacteria species showed a significant interaction between the material and the method of biofilm development as well as logarithms of $\mathrm{CFU} / \mathrm{mL}(P \leq .001)$. There was a wide increase in the $\mathrm{CFU} / \mathrm{mL}$ of $F$. nucleatum monospecies bacteria biofilm on all surfaces compared with
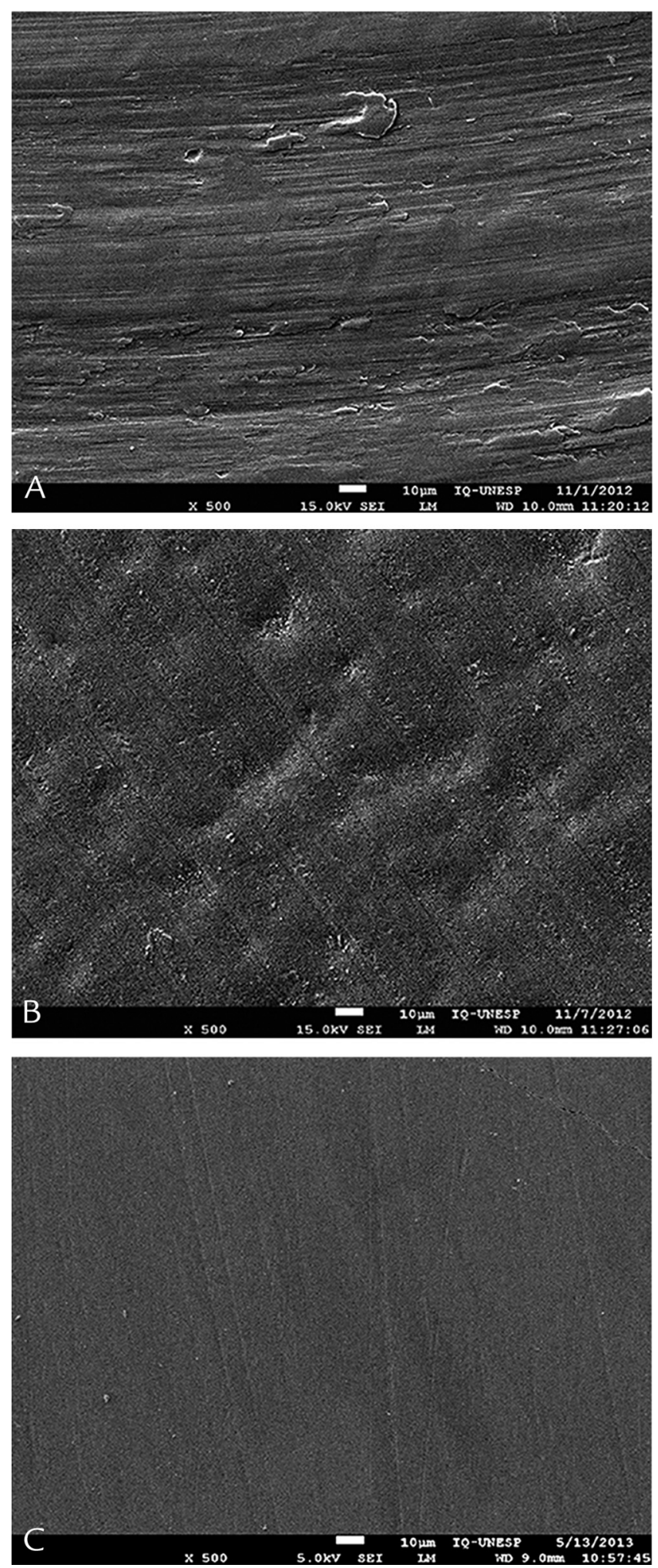

Figure 2. Scanning electron micrographs (original magnification, $\times 500$ ) of each material surface. A, $\mathrm{Ti} . \mathrm{B}, \mathrm{ZrO}_{2}$. C, Bovine enamel. Areas of interest were selected by setting each specimen at horizontal and vertical planes. 
P. gingivalis (Fig. 3A, B), but the materials did not affect the numbers of $F$. nucleatum $(P<.05)$. The effect of material on monospecies bacterial biofilms showed high numbers of $P$. gingivalis on $\mathrm{ZrO}_{2}$ surfaces and a significantly lower number on BE. Then the ability of mixed species bacteria to develop biofilm on the experimental and control groups was tested. The highest number of colonies was found on $\mathrm{BE}$; this number was always higher for F. nucleatum than P. gingivalis (Fig. 3C).

The viability of the bacteria grown on the material surfaces was similar. The differences in bacterial distribution on the tested substrates were confirmed by CLSM. Monospecies and mixed species biofilms with $P$. gingivalis on $\mathrm{Ti}$ and $\mathrm{ZrO}_{2}$ showed less colony spreading for all surfaces (Fig. 4A, B), but an intense biofilm on BE was observed (Fig. 4C). However, no statistically significant difference in $\mathrm{CFU} / \mathrm{mL}$ for the $F$. nucleatum biofilm was observed; for $\mathrm{ZrO}_{2}$, the cell numbers decreased after 7 days. High-resolution observations $(\times 40)$ of $F$. nucleatum revealed relatively large bacterial colonies and high intensity, or high biovolume, on $\mathrm{Ti}$ disks (Fig. 5A), in contrast to $\mathrm{ZrO}_{2}$ and BE, which had small and sparse bacterial colonies (Fig. 5B, C). Similarly, depth biofilm analysis showed that $F$. nucleatum was able to form more confluent and profound biofilms on $\mathrm{Ti}$ surfaces than on the other tested surfaces. In relation to mixed species bacteria biofilms, $\mathrm{ZrO}_{2}$ showed little biofilm, with a $12 \mu \mathrm{m}$ depth on disks and small-scattered cell clusters with large voids in comparison with Ti (Fig. 6A, B); the biofilm formed on the BE surface was notably deeper, up to $28 \mu \mathrm{m}$ in depth (Fig. 6C).

To investigate the effect of each material on the density of the biofilm, the confocal images were scanned and expressed as the bacterial number in terms of integrated intensity of pixels, with mean and SD. The data were consistent with CLSM images. The density of $F$. nucleatum biofilm on Ti surfaces was 3.2-fold higher than on $\mathrm{BE}$ (Fig. 7A). In contrast, $\mathrm{ZrO}_{2}$ showed the best results, with the lowest density values of monospecies and mixed species bacteria biofilm represented by the number of pixels. The density of $P$. gingivalis as monospecies biofilm on $\mathrm{ZrO}_{2}$ material was 3.0-fold lower than on $\mathrm{BE}$ and 3.4-fold lower than on Ti (Fig. 7B). Mixed species biofilm formed on BE showed biomass 1.2-fold higher than on $\mathrm{Ti}$ and 5.5-fold higher than on $\mathrm{ZrO}_{2}$ (Fig. 7C).

\section{DISCUSSION}

The results of this research suggest accepting the research hypothesis that the different material surfaces affect the quality and quantity of a mature anaerobic biofilm.

The surface roughness of the material surfaces seems to play a crucial role in bacteria adhesion and biofilm formation. ${ }^{22,27}$ The variable roughness was eliminated to


Figure 3. A, Mono Porphyromonas gingivalis. B, Mono Fusobacterium nucleatum. $\mathrm{C}$, Mixed species bacterial biofilm formed on $\mathrm{Ti}$ and $\mathrm{ZrO}_{2}$ implant abutment surfaces and on bovine enamel after 7 days of incubation ( $\log C F U / m L)$. Data are shown as mean $\pm S D(n=12)$. *\#Statistically significant differences among materials $(P<.05)$. 

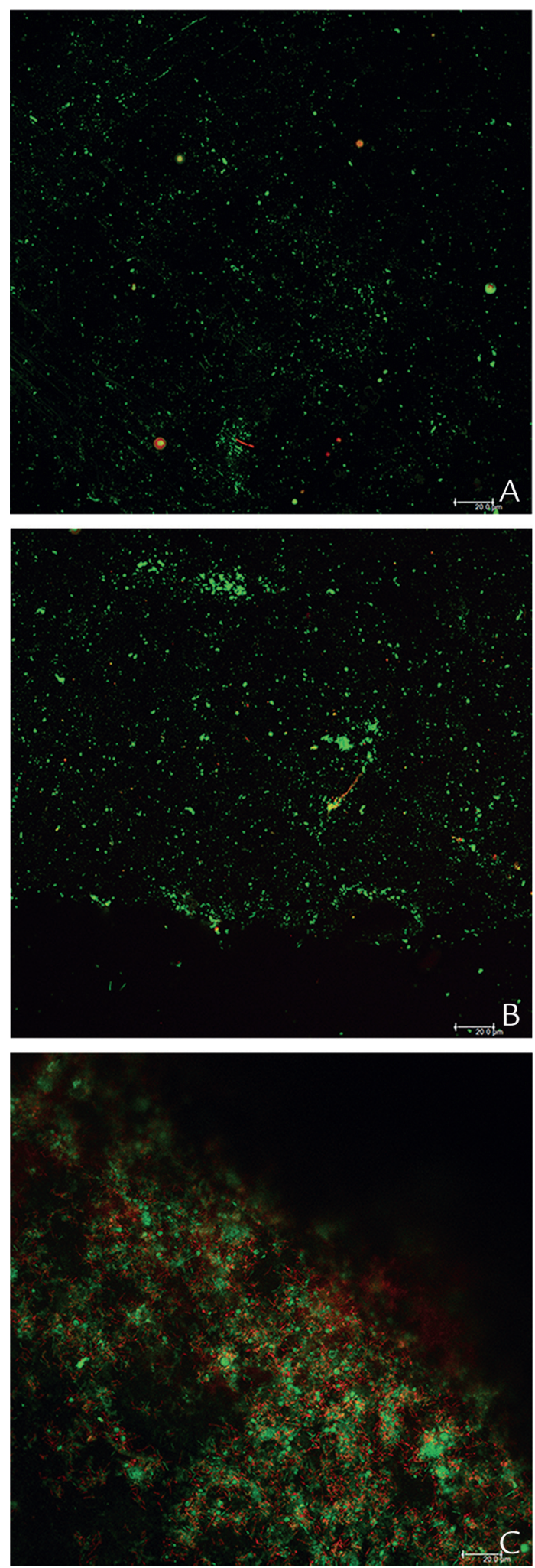

Figure 4. Cross-sectional images of Porphyromonas gingivalis biofilms that developed after 7 days of incubation. A, Ti. B, ZrO 2 . C, Bovine enamel. Dead cells stained red, live cells stained green.


Figure 5. Cross-sectional images of Fusobacterium nucleatum biofilms after 7 days of incubation. A, Ti. B, $\mathrm{ZrO}_{2}$. C, Bovine enamel. Dead cells stained red, live cells stained green. 

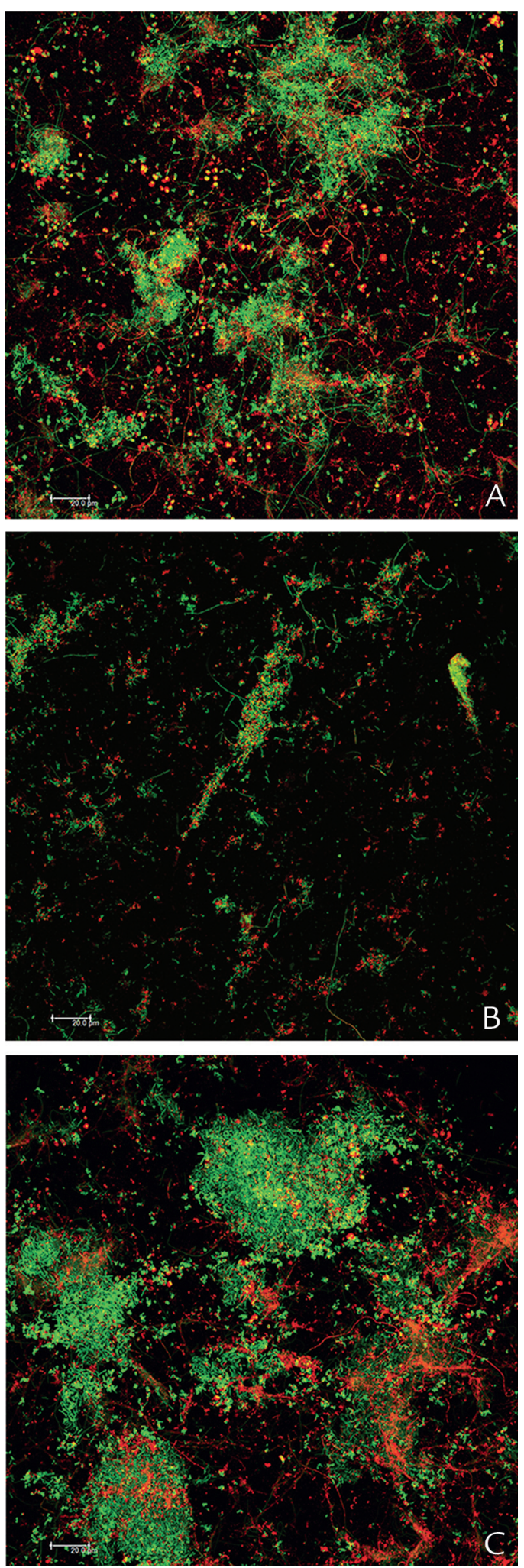

Figure 6. Cross-sectional images of mixed species Porphyromonas gingivalis and Fusobacterium nucleatum biofilms after 7 days of incubation. A, Ti. B, $\mathrm{ZrO}_{2}$. C, Bovine enamel. Dead cells stained red, live cells stained green.
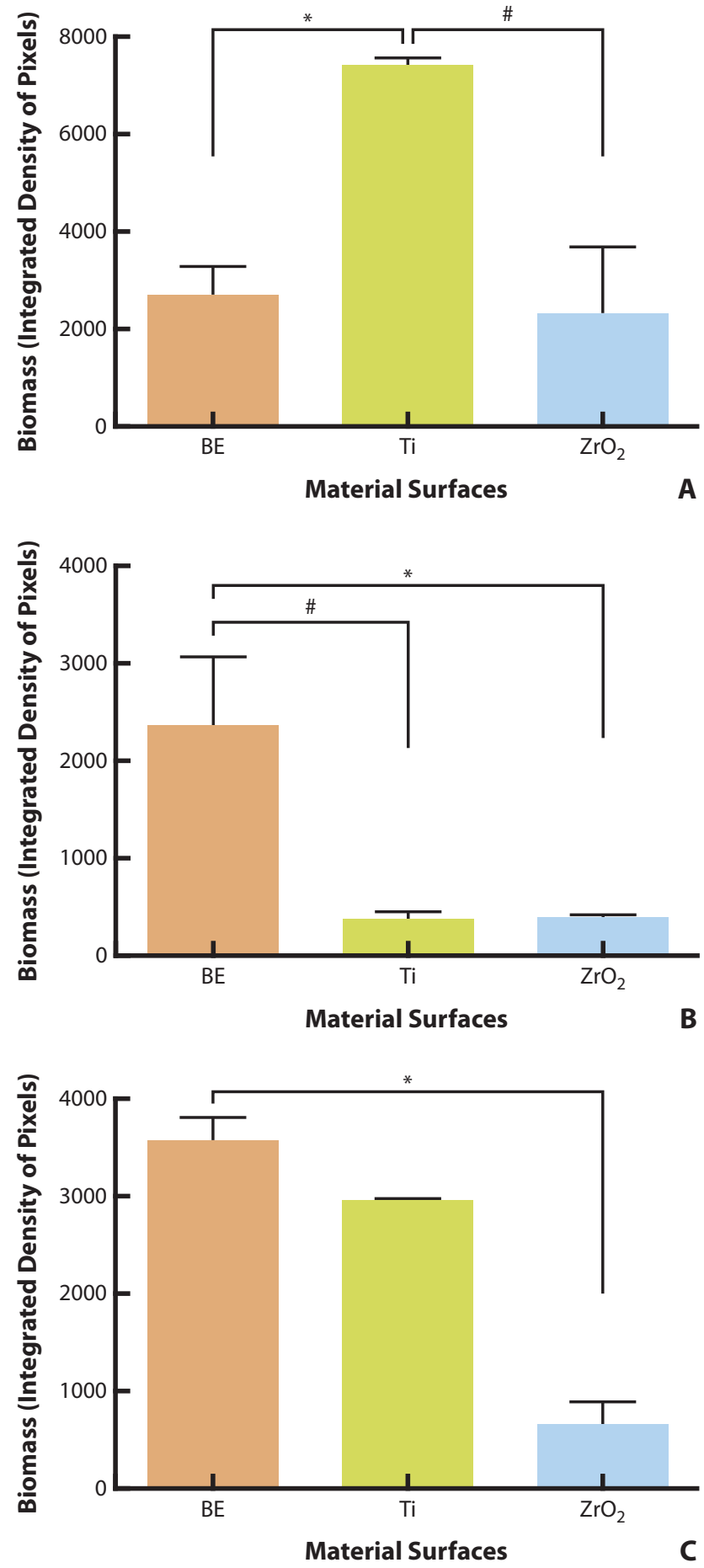

Figure 7. Quantitative analysis of biomass of monospecies and mixed biofilm for substrate. A, Integrated density of Fusobacterium nucleatum monospecies bacterial biofilm was significantly higher on Ti disks $(P=.016)$. B, For Porphyromonas gingivalis monospecies biofilms, integrated density was significantly higher on bovine enamel disks $(P=.02)$. $C$, For mixed species biofilms, significantly reduced integrated density was observed on $\mathrm{ZrO}_{2}$ disks $(P=.0012)$. Data shown as means $\pm \mathrm{SD}$ $(\mathrm{n}=3)$, with $P<.05$ indicating statistically significant difference among disk materials. 
maintain the homogeneity of the groups at an $R_{a}$ of about $0.2 \mu \mathrm{m}$ while evaluating the real effect of each material. ${ }^{28}$ Surface contact angle is also an important factor for the adhesion and growth of bacteria on different material surfaces. Because implant abutment surfaces are covered with an acquired pellicle, in vivo, the disks were immersed in sterilized saliva prior to biofilm development to simulate clinical conditions. The data showed that although all the material surfaces were hydrophilic, as determined by the contact angles for sessile water drops lower than 50 degrees, ${ }^{39}$ Ti presented the highest values. Furthermore, the contact angle data between the materials surfaces and diiodomethane revealed a higher lipophilic characteristic to BE. Bacteria express a wide diversity of complex molecules, such as lipopolysaccharide in the case of gram-negative bacteria, which gives the cell surface a net anionic charge (negative). The degree to which these structures influence the hydrophilic or hydrophobic characteristics is dependent on the structural components. ${ }^{18}$ Surfaces with polar and nonpolar properties, such as hydroxyapatite from enamel surfaces, can become electrostatically more attracted and bound to the different bacteria species. ${ }^{19}$ This chemical concept can explain why the mixed species bacterial biofilm exhibited the highest value for biomass of biofilm formed on enamel. Regarding the SFE, no difference among the materials was observed. A possible explanation is that the saliva coating formed onto the disks altered the surface energy of all the surfaces analyzed. The SFE of a material surface is reported to affect the initial adherence and biofilm formation of microorganisms, suggesting that those with low SFE would attract fewer bacteria than others with higher SFE. ${ }^{23}$ The high SFE can be interpreted as a high number of active ions on surfaces, which would increase the attraction forces for liquid (or bacteria) with the same chemical composition. However, no correlation was observed between SFE and biofilm formation, indicating that other properties from material surfaces such as surface chemical composition and the wettability of materials combined with bacterial strains and number of species used could be involved in this outcome.

Both F. nucleatum and P. gingivalis displayed intraspecies variability with regard to biofilm formation. The developed biofilm on the implant abutment surfaces, both $\mathrm{Ti}$ and $\mathrm{ZrO}_{2}$, were different from that formed on a typical tooth surface. In monospecies $P$. gingivalis biofilm, $\mathrm{ZrO}_{2}$ showed higher cell numbers than on other materials, and $F$. nucleatum did not show any differences in adhered cell numbers. These results were not consistent with CLSM, which could be considered a limitation of this in vitro study. A possible explanation is that monospecies bacterial biofilm on $\mathrm{ZrO}_{2}$ or Ti surfaces would be significantly thinner than on $\mathrm{BE}$ and that the cells could be detached from the disks during the ultrasound procedure. However, in the case of mixed species biofilm, their structure (by CLSM) and log CFU/mL were significantly different when comparing BE with both implant abutment material surfaces, demonstrating thicker biofilms with higher bacterial numbers after reaching the mature state (after 7 days). Some studies have also reported low but significant numbers of bacteria adhered to $\mathrm{ZrO}_{2}$ than to Ti surfaces. ${ }^{34}$ Streptococcus mutans was found in higher numbers on ceramic than other bacteria species such as Streptococcus sanguis, which seemed to have more affinity for Ti materials, but the reason for this is not yet known. In another recent study, different data were observed; $\mathrm{ZrO}_{2}$ attracted more Streptococcus oralis, Streptococcus mitis, Streptococcus salivarius, and Staphylococcus aureus biofilm than comparable variants of $\mathrm{Ti}$ or $\mathrm{Ti}$ alloys across the hydrophilicity or hydrophobicity characteristics. ${ }^{33}$ Likely the chemical elements from wall bacteria cells determine the type and quality of the interaction between microorganism and material surface. ${ }^{24}$ All those investigations were short-term evaluations ( $\leq 24$ hours) and study only early bacterial adhesion. In the present study, mature colonizers differed significantly between the monospecies and mixed species biofilms on $\mathrm{Ti}$ and $\mathrm{ZrO}_{2}$ materials. The time point corresponded to the formation of a barrier epithelium beginning at 1 to 2 weeks and completed at 6 to 8 weeks of healing. ${ }^{4}$ This is the most important period for bacterial adherence and for the development of biofilm on material surfaces due to the absence of a soft tissue protector.

\section{CONCLUSIONS}

The results indicated that in the case of mixed species bacterial biofilm, the number of cells and the density of the biofilm on $\mathrm{ZrO}_{2}$ were lower than on Ti materials. Physical chemical characteristics from different materials affect the pathogenic bacteria adhesion and their growth. Further studies using an oral microbial community may be able to show exactly what happens when a complex and natural microbiota combines with different implant abutment materials.

\section{REFERENCES}

1. Torresyap V, Moshaverinia A, Chee WW. Biofilms in restorative dentistry: a clinical report. J Prosthet Dent 2015;113:524-7.

2. Kornman KS. Mapping the pathogenesis of periodontitis: a new look. I Periodontol 2008:79:1560-8.

3. Litonjua LA, Cabanilla LL, Abbott LJ. Plaque formation and marginal gingivitis associated with restorative materials. Compend Contin Educ Dent 2012;33:e6-10.

4. Tomasi C, Tessarolo F, Caola I, Wennstrom J, Nollo G, Berglundh T. Morphogenesis of peri-implant mucosa revisited: an experimental study in humans. Clin Oral Implants Res 2014:25:997-1003.

5. Lindhe J, Meyle J, Group D of European Workshop on Periodontology. Periimplant diseases: consensus report of the Sixth European Workshop on Periodontology. J Clin Periodontol 2008;35:282-5.

6. Elter C, Heuer W, Demling A, Hannig M, Heidenblut T, Bach FW, et al. Supra- and subgingival biofilm formation on implant abutments with 
different surface characteristics. Int J Oral Maxillofac Implants 2008;23: 327-34.

7. Scarano A, Piattelli M, Caputi S, Favero GA, Piattelli A. Bacterial adhesion on commercially pure titanium and zirconium oxide disks: an in vivo human study. J Periodontol 2004;75:292-6.

8. Simonis $\mathrm{P}$, Dufour T, Tenenbaum H. Long-term implant survival and success: a 10-16-year follow-up of non-submerged dental implants. Clin Oral Implants Res 2010;21:772-7.

9. Aas JA, Paster BJ, Stokes LN, Olsen I, Dewhirst FE. Defining the normal bacterial flora of the oral cavity. J Clin Microbiol 2005;43: 5721-32.

10. Paster BJ, Olsen I, Aas JA, Dewhirst FE. The breadth of bacterial diversity in the human periodontal pocket and other oral sites. Periodontology 2000;2006(42):80-7.

11. Yang HW, Huang YF, Chou MY. Occurrence of Porphyromonas gingivalis and Tannerella forsythensis in periodontally diseased and healthy subjects. J Periodontol 2004;75:1077-83.

12. Van Winkelhoff AJ, Loos BG, van der Reijden WA, van der Velden U. Porphyromonas gingivalis, Bacteroides forsythus and other putative periodontal pathogens in subjects with and without periodontal destruction. J Clin Periodontol 2002;29:1023-8.

13. Holt SC, Kesavalu L, Walker S, Genco CA. Virulence factors of Porphyromonas gingivalis. Periodontol 2000;1999(20):168-238.

14. Listgarten MA, Lai CH. Comparative microbiological characteristics of failing implants and periodontally diseased teeth. J Periodontol 1999;70:431-7.

15. Kolenbrander PE, Andersen RN, Blehert DS, Egland PG, Foster JS, Palmer RJ. Communication among oral bacteria. Microbiol Mol Biol R 2002;66:486-505.

16. de Avila ED, de Molon RS, Vergani CE, Mollo FD, Salih V. The relationship between biofilm and physical-chemical properties of implant abutment materials for successful dental implants. Materials 2014;7:3651-62.

17. de Avila ED, de Molon RS, Spolidorio DMP, Mollo FD. Implications of surface and bulk properties of abutment implants and their degradation in the health of periodontal tissue. Materials 2013;6: 5951-66.

18. Doyle RJ. Contribution of the hydrophobic effect to microbial infection. Microbes Infect 2000;2:391-400.

19. Hazen KC, Lay JG, Hazen BW, Fu RC, Murthy S. Partial biochemical characterization of cell surface hydrophobicity and hydrophilicity of Candide albicans. Infect Immun 1990;58:3469-76.

20. Quirynen M, De Soete M, van Steenberghe D. Infectious risks for oral implants: a review of the literature. Clin Oral Implants Res 2002;13:1-19.

21. Teughels W, Van Assche N, Sliepen I, Quirynen M. Effect of material characteristics and/or surface topography on biofilm development. Clin Oral Implants Res 2006;17(suppl 2):68-81.

22. Quirynen M, Bollen CM. The influence of surface roughness and surface-free energy on supra- and subgingival plaque formation in man. A review of the literature. J Clin Periodontol 1995;22:1-14.

23. Mabboux F, Ponsonnet L, Morrier JJ, Jaffrezic N, Barsotti O. Surface free energy and bacterial retention to saliva-coated dental implant materials-an in vitro study. Colloids Surf B Biointerfaces 2004;39. 199-205.

24. Popovici J, White CP, Hoelle J, Kinkle BK, Lytle DA. Characterization of the cell surface properties of drinking water pathogens by microbial adhesion to hydrocarbon and electrophoretic mobility measurements. Colloids Surf B Biointerfaces 2014;118:126-32.

25. Tsukimura N, Yamada M, Iwasa F, Minamikawa H, Att W, Ueno T, et al Synergistic effects of UV photofunctionalization and micro-nano hybrid topography on the biological properties of titanium. Biomaterials 2011;32: 4358-68.
26. Yamada Y, Yamada M, Ueda T, Sakurai K. Reduction of biofilm formation on titanium surface with ultraviolet-C pre-irradiation. J Biomater Appl 2013.

27. Almaguer-Flores A, Olivares-Navarrete R, Wieland M, Ximenez-Fyvie LA, Schwartz Z, Boyan BD. Influence of topography and hydrophilicity on initial oral biofilm formation on microstructured titanium surfaces in vitro. Clin Oral Implants Res 2012;23:301-7.

28. Badihi Hauslich L, Sela MN, Steinberg D, Rosen G, Kohavi D. The adhesion of oral bacteria to modified titanium surfaces: role of plasma proteins and electrostatic forces. Clin Oral Implants Res 2013;24(suppl A100):49-56.

29. Burgers R, Eidt A, Frankenberger R, Rosentritt M, Schweikl H, Handel $G$, et al. The anti-adherence activity and bactericidal effect of microparticulate silver additives in composite resin materials. Arch Oral Biol 2009;54:595-601.

30. Leonhardt A, Bergstrom C, Lekholm U. Microbiologic diagnostics at titanium implants. Clin Implant Dent Relat Res 2003;5:226-32.

31. Nascimento C, Pita MS, Fernandes FH, Pedrazzi V, de Albuquerque Junior RF, Ribeiro RF. Bacterial adhesion on the titanium and zirconia abutment surfaces. Clin Oral Implants Res 2014;25:337-43.

32. Hahnel S, Wieser A, Lang R, Rosentritt M. Biofilm formation on the surface of modern implant abutment materials. Clin Oral Implants Res 2015;26: 1297-301.

33. Zhao B, van der Mei HC, Subbiahdoss G, de Vries J, Rustema-Abbing M, Kuijer R, et al. Soft tissue integration versus early biofilm formation on different dental implant materials. Dent Mater 2014;30:716-27.

34. Rimondini L, Cerroni L, Carrassi A, Torricelli P. Bacterial colonization of zirconia ceramic surfaces: an in vitro and in vivo study. Int J Oral Maxillofac Implants 2002;17:793-8.

35. Owens DK, Wendt RC. Estimation of surface free energy of polymers. J Appl Polym Sci 1969:13:1741

36. Burgers R, Gerlach T, Hahnel S, Schwarz F, Handel G, Gosau M. In vivo and in vitro biofilm formation on two different titanium implant surfaces. Clin Oral Implants Res 2010;21:156-64.

37. Lee BC, Jung GY, Kim DJ, Han JS. Initial bacterial adhesion on resin, titanium and zirconia in vitro. J Adv Prosthodont 2011;3:81-4.

38. Moura JS, da Silva WJ, Pereira T, Del Bel Cury AA, Rodrigues Garcia RC. Influence of acrylic resin polymerization methods and saliva on the adherence of four Candida species. J Prosthet Dent 2006; $96: 205-11$.

39. Van Oss CJ. Hydrophobic, hydrophilic and other interactions in epitopeparatope binding. Mol Immunol 1995;32:199-211.

40. Walker BN, Makinson OF, Peters MC. Enamel cracks. The role of enamel lamellae in caries initiation. Aust Dent J 1998;43:110-6.

\section{Corresponding author:}

Dr Erica Dorigatti de Avila

Department of Dental Materials and Prosthodontics

School of Dentistry at Araraquara

São Paulo State University (UNESP)

Rua Humaitá, 1680, Araraquara

São Paulo, 14801-903

BRAZIL

Email: erica.fobusp@yahoo.com.br

\section{Acknowledgments}

The authors thank Dr Miguel Jafelicce Jr for SEM images; Conexao Sistema de Protese for donating pure, commercially available titanium and zirconia stabilized with yttrium disks used in this study; and Dr Juliana Alvares Duarte Bonini Campos for her support with the statistical analysis.

Copyright () 2016 by the Editorial Council for The Journal of Prosthetic Dentistry. 